\title{
Evaluate and Intervene in Sensory Processing Disorders by Occupational Therapists in Early Intervention Teams of the North of Portugal
}

\author{
Aline Patriota Araújo ${ }^{1}$ and Ana Paula da Silva Pereira ${ }^{1}$ and Helena I.S. Reis ${ }^{2, *}$ \\ ${ }^{1}$ Research Center on Education (CIEd), Institute of Education, University of Minho, Braga, Portugal \\ ${ }^{2}$ Center for Innovative Care and Health Technology (ciTechCare), Polytechnic of Leiria, Leiria, Portugal
}

\begin{abstract}
Background: The National Early Childhood Intervention System of Portugal is an organized set of services under the responsibility of the Ministries of Health, Labor, and Social Security and Education aimed to support children between 0 and 6 years old and their families, and its mission is to ensure Early Childhood Intervention. At present, there is no research to support the extent of the use of sensory interventions in early intervention teams of Portugal.
\end{abstract}

Aims: This study aims to analyze and understand the role of occupational therapists who support children with Sensory Processing Dysfunction and their families in local Early Intervention Teams.

Methods: A qualitative and descriptive research was developed using semi-structured interviews. The interviews were conducted with ten occupational therapists who have worked in Early Intervention Teams in the North of Portugal for at least one year.

Results: Modulation and Praxis were the categories of Sensory Processing Dysfunction most identified. Families consider that Sensory Processing Dysfunctions interfere with children's performance in activities of daily living and playing. Early childhood educators report that Sensory Processing Dysfunctions influence the child's participation in food, playing, and in more structured and directed activities. To transfer skills, occupational therapists organize training for professionals, families, and early childhood educators.

Conclusion: The importance of collaborative work between professionals and the child's family is evident, and the support they provide in the natural environment and daily routines.

Keywords: Early Intervention, Natural Environments, Occupational Therapy, Sensory Processing, Sensory Processing Dysfunctions.

\section{INTRODUCTION}

Sensory Processing Disorder (SPD) is defined as the brain's difficulty in recording, modulating, and discriminating sensory stimuli to present an adaptive response [1]. In this way, a child will experience difficulties in using sensory information in daily life, with functional impairments such as decreased social participation, difficulty in occupational involvement, impairment in adaptive responses, emotional lability, difficulties in activities of daily living (ADL), in family and school relationship, and a delay in neuropsychomotor development [2-4].

Sensory processing difficulties limit a child's ability to achieve and maintain an optimal range of performance for adaptation and learning [5].

The Early Intervention Service in Portugal is regulated by Decree-Law 281/2009 of October 6 [6], which aimed to create a National Early Intervention System in Childhood (NEISC) which ensures all

*Address correspondence to this author at the Center for Innovative Care and Health Technology (ciTechCare), Politécnico de Leiria, Leiria, Portugal; Tel: +351 244845300; E-mail: helenaisabelsilvareis@gmail.com children with special educational needs receive a full learning experience in an inclusive school environment. It is a service where occupational therapists are integrated with other professionals from different disciplinary areas (doctors, nurses, psychologists, social workers, speech and language pathologists, physiotherapists, educators).

The practice of occupational therapists with children with SPD should be associated with the Theory of Sensory Integration of Ayres [7], which is described as an important and significant approach in the daily experiences of families [8]. This theory provides evidence of the ability to receive, classify, process, and make use of information originating in the body and the environment perceived by our senses (touch, gravity, position, and movement of the body, vision, smell, hearing, taste). Kuhaneck and Watling [7] affirm that the occupational therapist should act by supporting the families and parents of children with SPD in daily activities, playing, social participation, and routine functioning, aiming to make responsible all those involved in this support process.

When the occupational therapist supports children with SPD in Early Childhood Intervention, the therapist 
is then able to evaluate the child, his/her sensory processing and perform analysis of activities so that it is possible to propose, together with the family, changes to the environment, the adaptation of practices and the promotion of learning opportunities $[7,11]$. Moreover, professionals must understand the natural context in which the child is inserted, the functioning of the child and the family, as well as their concerns and priorities, and encourage and promote the participation of parents in supporting the child, thus aiming at concrete gains in their development [11-13].

The intervention plan should also be focused on the family and their concerns and based on the assessment and interpretation of SPD standards. EI best practices require professionals to promote active family participation in decision-making, development, and implementation of the plan, which should be flexible and individualized. Moreover, the family should actively participate in the evaluation, planning, and intervention $[14,15]$.

According to the Division for Early Childhood [16], early intervention support practices should be familycentered and aim at family empowerment and collaboration between the different actors involved in the support process. Collaboration is the understudy of family-centered practices because it involves sharing information, knowledge, and skills to achieve results and goals to improve the child's development. Professionals should therefore provide support in natural and inclusive environments during daily routines and activities and work with the family and other caregivers in learning sensitive and responsive ways to modify and adapt the physical, social, and time aspects, thereby promoting higher levels of participation and success in child's development [16].

Occupational therapists traditionally address sensory processing differences through therapy sessions and/or support and recommendations across home and school settings. Access to occupational therapy services in the Early Intervention Teams involves extensive waiting lists. The capacity to provide advice and support to parents and educators who are responsible for educating children with sensory processing differences for each day, five days per week, is extremely limited. Analyzing the kind of sensory processing interventions, assessment practices, and transfer of strategies by occupational therapists who work at the National Early Childhood Intervention System of Portugal is the goal of this study since there is no research in this regard.

\section{MATERIALS AND METHODS}

This study aimed to analyze and understand the role of occupational therapists in their support of children with SPD and their families, in the local Early Intervention Teams, in the northern part of Portugal. The research used a qualitative methodology and is classified as a descriptive and cross-sectional study. The research questions defined were:1) How does the occupational therapist evaluate the SDS of children supported by the local Early Intervention Teams?; 2) How does the Occupational Therapist integrate support for children with SDP in family routines and natural environments; 3) How does the occupational therapist transfer skills related to the support of SDP to the other professionals of the local Early Intervention Teams, the family, and the childhood educator, who support the child in preschool education?

\section{Participants}

The selection of participants was made by convenience and intentional, taking into account the possibility to deepen the research matter and the specificity of the theme under study (Patton, 2002). Participants were selected according to the following inclusion criteria: at least one year of experience in the local Early Intervention Teams in the northern part of Portugal. Thus, the study included 10 female occupational therapists, identified by a fictitious name, with experience working in the local Early Intervention Teams for between 1 and 17 years (see Table 1).

Table 1: Characterization of Participants

\begin{tabular}{|c|c|c|}
\hline Participants & Age & Years of experience in EI \\
\hline \hline Helena & 38 & 8 \\
\hline Maria & 38 & 5 \\
\hline Mónica & 41 & 17 \\
\hline Joana & 27 & 2 \\
\hline Sofia & 27 & 3 \\
\hline Gertrudes & 27 & 6 \\
\hline Isabel & 41 & 6 \\
\hline Maria P. & 29 & 2 \\
\hline Mariana R. & 27 & 3 \\
\hline Mariana & 45 & 1 \\
\hline
\end{tabular}




\section{Instrument of Data Collection and Procedures}

A semi-structured interview was used as a data collection tool, given that an interview enables the researcher to collect descriptive data in the subjects' language, making it possible to intuitively create an idea about the way subjects interpret the phenomena under study. We first created an interview guide with a set of semi-structured questions presented according to an order that made sense to our study goals. The validation of this preliminary interview guide included the interview of a professional, followed by an in-depth analysis conducted by a specialist in qualitative research. This process allowed for the revision of content, the format of questions, language, and also to confirm that the questions were compatible with the research goals.

The research was approved by the scientific council of the institute. Informed consent for participation in the research was signed by the participants (occupational therapists), in accordance with the Declaration of Helsinki and The Oviedo Convention, in which permission was requested for audio recording during the individual recorded session which was used in subsequent data analysis. To optimize the collaboration process of the participants in the COVID19 pandemic, the interviews were conducted online through the WhatsApp and Skype platforms with an average duration of 30 minutes.

\section{Data Analysis}

After being transcribed, the interviews were analyzed. The data analysis of this study was carried out through content analysis since the data collection instrument was the semi-structured interview. Content analysis allows the researcher to analyze the meanings found in the interviews (described texts or communication). Content analysis followed three steps: 1) pre-analysis; 2) exploitation of the material; 3) interpretation of the results [17].

In order to create our system of categories, we followed two processes: one deductive, by starting from a set of predetermined categories grounded on our study goals and theoretical framework: one inductive, by elaborating new categories and subcategories that emerged from data. Following the definition of this categorization, we determined inter-rater reliability in order to ensure a degree of agreement between researchers regarding the system of categories that had been defined. To do so, we asked for the collaboration of two external observers, both familiar with the phenomenon under study and with the content analysis technique [17] (see Figure 1).

A set of techniques was used for assessing the trustworthiness of this study, namely: credibility, through the technique of peer debriefing; validation, through member checks; conformability, through a reflective journal; and transferability, through a detailed description of all the particularities of this empirical study [18]

\section{RESULTS AND DISCUSSION}

Our results are presented by crossing the perspectives of the different participants, on the grounds of this study's three research questions, according to the previously defined categories.

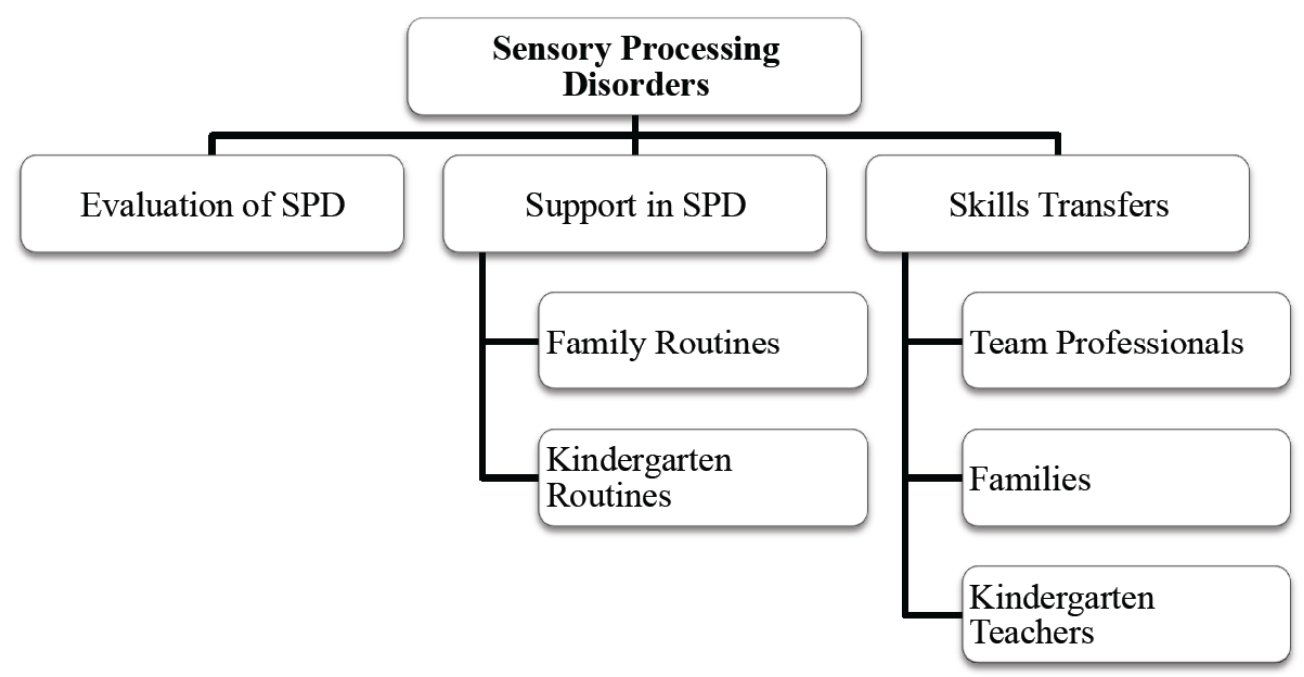

Figure 1: Categories and Subcategories. 


\section{Evaluation of Sensory Processing Dysfunctions}

Most of the professionals identified the categories of Modulation and Praxis as the most common categories of SPD in children supported by the local Early Intervention Teams: "Praxis and Modulation are the most identified dysfunctions in support of Early Intervention in Childhood" (Monica). Modulation is a critical process of the child's ability to engage in daily activities and to filter out the relevant and necessary sensations for the effective execution of the activity in which they are involved. In this way, modulation to sensory input is a critical capacity for the child to be able to maintain a good level of alertness and attention in performing tasks, social relations, and their capacity for self-regulation. When modulation is inadequate, the child's attention is dispersed considering the challenges imposed by the context or the environment that he/she may be in.

Children with modulation disorder commonly demonstrated such limitations:: 1) decreased social participation; 2) low self-esteem; 3) difficulties in activities of daily life and school; 4) anxiety and disorders in their ability to regulate their reactions with others and 5) changes in development [20].

According to most of the participants in this study, sensory modulation disorders manifest themselves more clearly in children through hyperreactivity, more specifically in the form of tactile defense. Children with tactile defense are disorganized and present aversive behaviors, more frequently, concerning some stimuli. This perspective is also defended by research that shows that hyperreactive children receive stimuli with greater intensity and present irritability, fear, and aggressiveness [21].

Aversive responses to sensory stimuli restrict the child's interests in activities, impacting their behavior in situations of play and interaction [23]. Children with tactile defense demonstrate behaviors of aversion and intolerance more easily, both about some textures and with some activities that integrate their daily routines, such as bathing, having a haircut, and feeding [24].

Most of the participants in this study report that SPD at the modulation level is more evident in feeding moments, which translates into difficulties in accepting new foods, with different textures and temperatures "Difficulty in eating soup and eating solids" (Sofia). This result is also supported by several authors who report that the daily stimuli are so unpleasant for these children (hyperreactive) that they limit their participation in daily activities and routines [3,21,23].

Another SPD identified by the participants is dyspraxia: "We identified more Modulation and Praxis SPD" (Maria). This disorder is related to a problem of organization and motor planning underlying an action [5]. Ayres [9] considered that the ability to process and integrate sensations was the basis for developing body schemes and, consequently, motor planning. Functionally, praxis difficulties, exhibited by children at early ages, are often manifested by delays in development and participation in ADLs, especially in self-care activities (such as fastening buttons, coats, blowing the nose).

Regarding the evaluation of SPD, most participants report that the most used instruments are formal instruments, highlighting at this level the Sensory Processing Measure for Preschoolers (SPM-P): "I use the SPM-P to screen modulation dysfunctions" (Gertrudes). They reported, however, that they adopt formal procedures such as observations in the natural environments and the routine moments of the child and his/her family.

According to Reis, Gomes, and Dixe [26], the SPM$P$ is an important instrument in the screening of SPD and evaluates the functioning and sensory processing of the child in modulation, praxis, and social participation. It is also worth mentioning the possibility of the child being able to be evaluated, with this instrument, in his/her natural environment: home and kindergarten.

Most occupational therapists report that to evaluate SPD, observations should be carried out in the child's natural environments and the main moments of routine: "SPD can be evaluated with spontaneous observations" (Maria P.). The evaluation of the child by professionals in natural environments is more realistic about the daily activities of children, as well as the strategies necessary to enhance development in daily routines.

El assessment should take place in the child's natural environment and his/her family, with materials and familiar people to them. Evaluation in the natural environment and routines of the child and his/her family allows obtaining a real picture of behavior and development and greater family involvement in this process. The appreciation of the importance of assessing SPDs in natural environments is also reinforced by Bundy and Lane (1) to provide critical 
evidence justifying changes in the levels of performance and participation of the child in his/her day-to-day routines.

\section{Support in Sensory Processing Dysfunctions}

\section{Family Routines}

Most of the participants in this study reported that SPDs involve difficulties in the child's participation in some ADLs. According to Isabel, the parents of one's child she supports report difficulties in their children's eating habits, particularly food selectivity (difficulties in accepting and tasting new foods and textures). This selectivity can be so severe that it has a framework in the diagnostic manual, DSM 5 [27], and is called "Avoidant/restrictive food intake disorder". This classification describes children who avoid some foods due to some sensory aspects, such as taste, texture, appearance, smell, and color [28, 29].

This result is also verified by some other researchers [30], who verified that children with SPD presented problems with food selectivity, which significantly decreased the intake and acceptance of new foods. These aspects condition the possibility of the child having a varied diet, both in quantity and quality. Children with food selectivity are described by parents as children who seek to control their preferences at mealtime so that they can deal with situations of fear and anxiety [31].

Another moment of daily activity, identified by the participants, concerns issues of hygiene: bathing, brushing teeth, cutting nails, and hair: "Cutting hair, nails, and dressing; children have reactivity to some clothes" (Mariana). Several authors report that these moments of hygiene can be painful for children with sensory modulation disorder [3, 21, 24, 25].

The participants also mention that some of the children they support show difficulty in motor planning (praxis) because they do not know how to coordinate certain motor actions that involve planning and sequencing: "They do not know how to manage their strength and trip over each other" (Gertrude). Children with dyspraxia have their participation affected in ADLs. If praxis has altered executive functions, it can affect the child's participation both from the point of ideation (what he/she is supposed to do?) and from the point of view of motor execution (What type of motor planning is necessary?) in the daily activities in which the child participates in, such as at the time of feeding or at the time of dressing and undressing [5].
The moment of play is another activity that the participants identify as being difficult in children with SPD: "they do not play with other friends, are sometimes socially awkward, and do not wait for their turn" (Mariana). Playing is impaired because impulsive, disorganized, and inappropriate behaviors occur, which can lead to avoidance of the families themselves in outings with the child (e.g., trips to the park) [19].

In fact, SPD may affect children's participation and social interaction. This perspective is also supported by research, stating that some children do not know how to play, are disorganized, spread toys, do not perceive how to manage strength, and often bump into other children unintentionally [21].

\section{Kindergarten Routines}

According to most participants, the childhood educators report that SPD affects the child's diet: "More concerns in food ADL" (Helena); and play: "Children always prefer the same games and in the same places" (Sofia) and targeted activities: "More directed work" (Maria P.). In fact, according to Nesayan and collaborators [32], SPD also affects participation in home and school routine activities and may restrict the children's social, cognitive, and sensorimotor development. SPD negatively influences adaptive behavior like eating, sleeping, and behaviors related to bath time and bedtime. At mealtimes, participants reported that the children's educators identify the same concerns as the families: food selectivity and rejection of new foods: "Food selectivity, difficulty in the introduction of solids and sitting at the table with peers" (Mariana R.).

In playing, most participants reported that children have difficulties in social interaction, choosing and changing games: "A form of playing to look for stimuli never changes and is without any creativity" (Mariana R.). Children with tactile defense (tactile hyperreactivity) avoid some activities developed in kindergartens, such as paints, modeling folders, or paintings with their hands, depriving themselves of participating in dynamics that are part of the experiences of most children. On the other hand, children with gravitational insecurity (vestibular hyperreactivity) avoid playgrounds, namely playing on the slide, on the swing, or participating in activities that require movement [21]. Children with SPD do not seem to perceive certain stimuli and have little interest in exploring the environment [22]. Chu [33] also identified that SPD could cause children not to have good body awareness, thus not favoring efficient participation in 
play and social interaction, isolating themselves from their peer group.

The participants reported that the childhood educators consider that the directed activity presents more challenges for these children because it requires higher levels of attention and concentration: "Tasks that require too much attention and recreation" (Mariana R.). The difficulties in attention, concentration and learning in children with SPD are reported by several authors [10, 19, 22]. Children with SPD have difficulties organizing their bodies in their specific environment, seeking more sensations, being restless, and starting a proposed activity but eventually losing focus, not completing the activity $[3,5,21,25]$.

\section{Transfer of Skills}

\section{Team Professionals}

When asked about how the professionals transfer skills to the other professionals of the team, most participants answered that this transfer is carried out during team training and by the observation and demonstration of that in the child's natural environments (home and kindergarten): "There exists internal team training" (Monica). In fact, occupational therapists can help other professionals in El teams to use activities and strategies to support children with SPD [34].

Similarly, most participants stated that observing routines and focusing on the environment are ways to transfer skills to other team professionals, families, and childhood educators. In their support of children in El with SPD, occupational therapists can modify environments and adapt some practices together with families and educators.

The promotion of sensory experiences in natural environments allows for more stimulating environments and more significant sensory experiences for the child $[12,35]$.

These results are consistent with DEC recommendations [16] in valuing natural environments as enhancers of quality practices in supporting the development and learning of children and their families. DEC also reinforces the notion that professionals who provide services and support in natural environments, support the family and educators in modifying and adapting physical, social, and time aspects, help to create effective and functional learning opportunities for the child. Regarding the internal training that the participants stated, the DEC states that the training sessions within the teams promote the interaction of professionals who support children, the sharing of knowledge and experiences, thus enhancing the child's learning [16].

\section{Families}

Most participants report that the transfer of skills to the family takes place during the moments of home visits with the family: "Simply demonstrating the strategies in the natural environment" (Monica). The occupational therapist needs to understand the context and functioning of the child and the family to be able to help, not only in the functional participation of the child in their context but also in the participation of parents in support of children with SPD [12].

The support strategies are based on the patterns of change of the child's sensory processing, are centered on the family, and are transmitted to the parents clearly and objectively. These strategies should be organized, prioritized, and implemented according to the concerns and priorities of families, considering the daily life routines of the child and his/her family.

According to DEC, professionals should empower and strengthen parenting knowledge and skills and parenting competence and confidence in ways that are flexible, individualized, and tailored to the family's preferences [16].

\section{Kindergarten Teachers}

According to the participants of this study, EI practitioners use coaching or consultation strategies with kindergarten teachers to facilitate positive adultchild interactions and instruction intentionally designed to promote child learning and development.

In Portugal, Decree-Law 281/2009 [6] defines that El professionals must articulate with educators in nurseries and kindergartens where the child is included. At this level, they highlight: "Pass on strategies clearly in the context of kindergarten". The appreciation of the transfer of skills in the child's natural environment and his/her family is also highlighted by Raver and Childress [14], where they affirm that children learn and develop in different environments in their moments of interaction over time.

\section{CONCLUSION}

Sensory processing is the registration and interpretation of sensory information to create an adaptive behavior based on task demands. 
In this way, SPD may affect learning, motor coordination, behavior, language, or sensorimotor development, thus hindering the child's participation in daily life activities [36-37].

In this study, it was evident that the most identified SPD by the participants were grouped into two categories based on Miller's model: Sensory Modulation and Motor Base Disorder (dyspraxia) (3).

Another conclusion to be highlighted is the type of evaluation of the SPDs performed by the participants in the study. Although most occupational therapists report the use of the Sensory Processing Measure for Preschoolers scale or the Sensory Profile, the appreciation they make for the importance of direct observation of the child in natural environments as an evaluation process performed by the local teams of Early Intervention stands out. This appreciation of the natural environment in the evaluation process in the $\mathrm{El}$ of the child is in line with the perspectives of Bundy and Lane (1).

Assessment in natural environments allows not only the possibility to obtain a real picture of the child's skills, needs, and interests but also to define the priority goals of intervention.

The conclusion of this study also focuses on the difficulties that families demonstrate in dealing with SPD. The participants reported that many families say that having a child with SPD can become extremely exhausting since these children, in the vast majority of cases, are challenged in their participation in tasks with oppositive, disorganized, and unregulated behaviors.

The results of this study also show that active family participation in the evaluation and intervention process is not only important for the effectiveness of the child's support process but also informative and emotional support to parents. In this way, as a member of the early intervention team, the occupational therapist has personal responsibilities with the other practitioners and the family in the enrichment and expansion of knowledge in sensory integration theory and practice. Therefore, effective communication and collaboration between the family and team professionals should be maximized, both in the moments of training in this theme and the moments of the transfer of skills related to SPD.

\section{LIMITATIONS AND RECOMMENDATIONS OF THE STUDY}

The current study had some limitations. The inexperienced researcher may be unable to perform an accurate analysis because they do not have the knowledge and skills required. This could affect the authenticity. We also highlight the reduced number of participants as a result of the COVID-19 pandemic. First, it was difficult to get therapists' participation because, at this point, everyone was overwhelmed with online work, and second, we were forced to rethink the logistics of the interviews, which went from face-to-face to online. The researcher's presence may bias responses in the interviews. The participants belong to the same geographic region, which can be characterized by some uniformity of experiences, and practices and, in this way, could be another limitation of the study.

Considering the study results, we highlight as a recommendation the importance of training early childhood intervention professionals who support children with SPD and their families in the area of sensory processing. For future studies, it is important to analyze the type of strategies defined for children with SPD and how they are included in routine moments and the participation of the family, the childhood educator, and the local Early Intervention teams professionals in this process.

\section{FUNDING}

The authors acknowledge all the support provided by the Center for Innovative Care and Health Technology (ciTechcare), Polytechnic of Leiria, Leiria, Portugal (UIDB/05704/2020 and UIDP/05704/2020).

This work is also funded by CIEd - Research Centre on Education, Institute of Education, University of Minho, projects UIDB/01661/2020 and UIDP/01661/2020, through national funds of FCT/MCTES-PT.

\section{REFERENCES}

[1] Bundy A, Lane SJ. Sensory Integration: Theory and Practice. 3rd ed. Philadelphia, PA: F. A. Davis Company; 2020.

[2] Mattos JC, D'Antino MEF, Cysneiros RM. Evidências de confiabilidade e validade do instrumento de avaliação sensorial Sensory Profile: Um estudo preliminar [Evidence of reliability and validity of the sensory profile assessment instrument: A preliminary study]. Psicologia: Teoria e Prática 2019; 21(2): 75-98 https://doi.org/10.5935/1980-6906/psicologia.v21n2p99-121

[3] Miller LJ, Anzalone ME, Lane SJ, Cermak SA, Osten ET. Concept evolution in sensory integration: a proposed nosology for diagnosis. Am J Occup Ther 2007; 61(2): 13540.

https://doi.org/10.5014/ajot.61.2.135 
[4] El Shemy SA, Mohamed NE. Effect of sensory integration on motor performance and balance in children with developmental coordination disorder: $A$ randomized controlled trial. Int J Ther Rehabil Res 2017; 6(1): 1-9. https://doi.org/10.5455/ijtrr.000000213

[5] Cabrera SJ, Ayuso DR, Gil GR, Juárez JM. Assessment of sensory processing characteristics in children between 3 and 11 years old: A systematic review. Front Pediatr 2017; 5: 118.

\section{https://doi.org/10.3389/fped.2017.00057}

[6] República Dd. Decreee Law $n^{\circ} 281$ Cria o Sistema Nacional de Intervenção Precoce na Infância. In: I S, editor. Diário da República 2009, n. ${ }^{\circ}$ 172/1999, Série I-A de 1999-07-26, páginas 4680 - 4681 .

[7] Kuhaneck HM, Watling R. Occupational therapy: Meeting the needs of families of people with autism spectrum disorder. Am J Occup Ther 2015; 69(5): 6905170010p1-5 https://doi.org/10.5014/ajot.2015.019562

[8] Ashburner J, Rodger S, Ziviani J, Jones J. Occupational therapy services for people with autism spectrum disorders: Current state of play, use of evidence and future learning priorities. Aust Occup Ther J 2014; 61(2): 110-20. https://doi.org/10.1111/1440-1630.12083

[9] Ayres AJ. Sensory integration and the child: Understanding hidden sensory challenges. Los Angeles: Western Psychological Services; 2005.

[10] Kilroy E, Aziz-Zadeh L, Cermak S. Ayres theories of autism and sensory integration revisited: What contemporary neuroscience has to say. Brain Sci 2019; 9(3): 68. https://doi.org/10.3390/brainsci9030068

[11] Bowyer P, Moore CC, Tiongco CG, Tkach MM, Thom C. Perspectives of occupational therapists on the challenges of early intervention practice: A pilot study. J Occup Ther Sch Early Interv 2017; 10(1): 18-26. https://doi.org/10.1080/19411243.2016.1257966

[12] Gibbs V, Toth-Cohen S. Family-centered occupational therapy and telerehabilitation for children with autism spectrum disorder. Occup Ther Health Care 2011(4): 298314.

https://doi.org/10.3109/07380577.2011.606460

[13] Segal R. Family routines and rituals: A context for occupational therapy interventions. Am J Occup Ther 2004; 58: 499-508.

https://doi.org/10.5014/ajot.58.5.499

[14] Raver SA, Childress DC. Family-centered early intervention: Supporting infants and toddlers in natural environments. Baltimore: Paul H. Brooks Publishing; 2015.

[15] Minard C. The underutilization of occupational therapy in transdisciplinary early intervention services. J Occup Ther Sch Early Interv 2018; 11(1): 15-20.

https://doi.org/10.1080/19411243.2017.1408441

[16] DEC. Division for Early Childhood recommended practices in early intervention/early childhood special education 2014. Available at: https://www.dec-sped.org/dec-recommendedpractices

[17] Bardin L. Análise de conteúdo [Content analysis]. 2nd ed: Edições 2015; 70: ISBN: 9789724415062.

[18] Lincoln SY, Guba EG. Naturalistic inquiry. Thousand Oaks, CA: Sage; 1985 https://doi.org/10.1016/0147-1767(85)90062-8

[19] Lane SJ, Mailloux Z, Schoen S, Bundy A, May-Benson TA, Parham LD, et al. Neural foundations of Ayres Sensory Integration. Brain Sci 2019; 9(7):153. https://doi.org/10.3390/brainsci9070153

[20] Parham LD, Mailloux Z. Sensory integration. In: Case-Smith J, Ed. Occupational therapy for children: Volve; 1995; pp. 329-81.
[21] Dunn W. Supporting children to participate successfully in everyday life by using sensory processing knowledge. Infants Young Child 2007; 20(2): 84-101. https://doi.org/10.1097/01.IYC.0000264477.05076.5d

[22] James K, Millera LJ, Schaaf R, Nielsene DM, Schoen SA. Phenotypes within sensory modulation dysfunction. Compr Psychiatry 2011; 52: 715-24.

https://doi.org/10.1016/j.comppsych.2010.11.010

[23] Schaaf RC, Miller LJ, Seawell D, O'Keefe S. Children with disturbances in sensory processing: A pilot study examining the role of the parasympathetic nervous system. Am J Occup Ther 2003; 57(4): 442-9. https://doi.org/10.5014/ajot.57.4.442

[24] Spies R, Van Rensburg E. The experiences of parents with tactile defensive children. S Afr J Occup Ther 2012; 42(3): 711.

[25] Pérez-Fonseca RA, Burguillos-Torres GE, Castillo-Velásquez VG, Moreno-Zuleta N, Fonseca-Angulo RI, Blumtritt C, et al. Sensory profile in children with autism disorder and children with typical development. Rev Mex Neurociencia 2019; 20(5): 229-36.

https://doi.org/10.24875/RMN.M19000019

[26] Reis HS, Gomes MD, Dixe MdA. Semantic, conceptual, experiential, and idiomatic equivalence of sensory processing measure for preschoolers. Siglo Cero 2019; 50(4): 61-73. https://doi.org/10.14201/scero20195046173

[27] APA. Diagnostic and statistical manual of mental disorders (DSM-5). 5th ed. Washington, USA: American Psychiatric Association; 2013. Available https://www.psychiatry.org/psychiatrists/practice/dsm

[28] Hubbard KL, Anderson SE, Curtin C, Must A, Bandini LG. A comparison of food refusal related to characteristics of food in children with autism spectrum disorder and typically developing children. J Acad Nutr Diet 2014; 114: 1981-7. https://doi.org/10.1016/j.jand.2014.04.017

[29] Postorino V, Sanges V, Giovagnoli G, Fatta LM, De Peppo L, Armando $\mathrm{M}$, et al. Clinical differences in children with autism spectrum disorder with and without food selectivity. Appetite 2015; 92: 126-32.

https://doi.org/10.1016/j.appet.2015.05.016

[30] Rocha GS, Júnior FC, Lima ND, Silva MV, Machado A Pereira IC, et al. Análise da seletividade alimentar de pessoas com transtorno do espectro autista [Analysis of food selectivity in people with autism spectrum disorder]. Revista Eletrônica Acervo Saúde 2019; 24: 1-8. https://doi.org/10.25248/reas.e538.2019

[31] Angel MA. Selective eaters and tactile sensitivity: A review of classification and treatment methods that address anxiety and support a child's need for a sense of control. ICAN: Infant, Child, \& Adolescent Nutrition 2010; 2(5): 299-303. https://doi.org/10.1177/1941406410382904

[32] Ben-Sasson A, Cermak SA, Orsmond GI, Tager-Flusberg $\mathrm{H}$, Carter AS, Kadlec MB, et al. Extreme sensory modulation behaviors in toddlers with autism spectrum disorders. Am J Occup Ther 2007; 61(5): 584-92.

https://doi.org/10.5014/ajot.61.5.584

[33] Chu VWT. Assessing proprioception in children: A review. J Mot Behav 2017; 49(4): 458-66. https://doi.org/10.1080/00222895.2016.1241744

[34] May-Benson TA, Koomar JA. Systematic review of the research evidence examining the effectiveness of interventions using a sensory integrative approach for children. Am J Occup Ther 2010; 64(3): 403-14. https://doi.org/10.5014/ajot.2010.09071

[35] Cohn E, Miller LJ, Tickle-Degnen L. Parental hopes for therapy outcomes: Children with sensory modulation disorders. Am J Occup Ther 2000; 54(1): 36-43. https://doi.org/10.5014/ajot.54.1.36 
[36] Chien CW, Rodger S, Copley J, Branjerdporn G, Taggart C. Sensory processing and its relationship with children's daily life participation. Phys Occup Ther Pediatr 2016; 36(1): 7387.

https://doi.org/10.3109/01942638.2015.1040573
[37] Crozier SC, Goodson JZ, Mackay ML, Synnes AR, Grunau $\mathrm{RE}$, Miller SP, et al. Sensory processing patterns in children born very preterm. Am J Occup Ther 2016; 70(1): 7001220050 p1-7.

https://doi.org/10.5014/ajot.2016.018747

Received on 23-09-2021

Accepted on 15-11-2021

Published on 08-12-2021

https://doi.org/10.6000/2292-2598.2021.09.06.1

(ㄷ) 2021 Araújo et al.; Licensee Lifescience Global.

This is an open access article licensed under the terms of the Creative Commons Attribution License (http://creativecommons.org/licenses/by/4.0/) which permits unrestricted use, distribution and reproduction in any medium, provided the work is properly cited. 